\title{
AGROTEKNIKA
}

ISSN: 2685-3450 (Online)

www.agroteknika.id

ISSN: 2685-3450 (Print)

\section{Penerapan Teknologi Visible-Near Infrared Spectroscopy untuk Prediksi Cepat dan Simultan Kadar Air Buah Melon (Cucumis melo L.) Golden}

\section{Application of Visible-Near Infrared Spectroscopy Technology for Rapid and Simultaneous Prediction of Water Content in Golden Melon (Cucumis melo L.) Fruit}

\author{
Yuda Hadiwijaya*,1, Kusumiyati ${ }^{2}$, Agus Arip Munawar ${ }^{3}$
}

\begin{abstract}
${ }^{1}$ Program Studi Magister Agronomi, Fakultas Pertanian, Universitas Padjadjaran, Indonesia ${ }^{2}$ Departemen Budidaya Pertanian, Fakultas Pertanian, Universitas Padjadjaran, Indonesia ${ }^{3}$ Program Studi Teknik Pertanian, Fakultas Pertanian, Universitas Syiah Kuala, Indonesia
\end{abstract}

\author{
*Penulis Korespondesi \\ Email: yuda09001@mail.unpad.ac.id
}

\begin{abstract}
Abstrak. Kadar air merupakan salah satu atribut kualitas yang penting pada komoditas hortikultura. Penetapan kadar air buah melon dengan metode konvensional memakan waktu yang lama dan perlu merusak sampel buah. Penelitian ini bertujuan untuk memprediksi kadar air buah melon golden menggunakan teknologi visible-near infrared spectroscopy (Vis-NIRS). Metode koreksi spektra orthogonal signal correction (OSC) diterapkan pada spektra original untuk meningkatkan kehandalan model kalibrasi. Partial least squares regression (PLSR) digunakan sebagai metode pendekatan regresi untuk mengekstraksi data spektra Vis-NIRS. Hasil penelitian membuktikan bahwa Vis-NIRS dapat diandalkan untuk memprediksi kadar air buah melon golden. Metode koreksi spektra OSC mampu memperkecil jumlah principal component (PC) pada spektra original. Linieritas pada model kalibrasi menggunakan spektra OSC tercatat memperoleh nilai tertinggi sebesar 0,92. Ratio of performance to deviation (RPD) pada spektra OSC menampilkan nilai tertinggi pula yaitu 3,63. Model kalibrasi yang diperoleh pada penelitian ini dapat ditransfer ke dalam spektrometer Vis-NIRS untuk prediksi kadar air melon golden secara cepat dan simultan.
\end{abstract} Kata kunci: visible-near infrared spectroscopy, kadar air, buah melon golden

Abstract. Water content is an important quality attribute of horticultural commodities. Determination of water content in melon fruit using conventional methods is time-consuming and required to destruct the fruit samples. The research aimed to predict the water content of golden melon using visible-near infrared spectroscopy (Vis-NIRS) technology. Orthogonal signal correction (OSC) spectra correction was applied to the original spectra to increase the calibration model's reliability. Partial least squares regression (PLSR) was utilized as a regression approach method to extract Vis-NIRS spectra data. The results proved that Vis-NIRS was reliable to predict water content in golden melon. OSC spectra correction was able to minimize the number of principal components $(P C)$ in the original spectra. Linearity in the calibration model using OSC spectra yielded the highest value of 0.92. The ratio of performance to deviation (RPD) in OSC spectra displayed the highest score of 3.63. This research's acquired calibration model could be transferred into a Vis-NIRS spectrometer for rapid and simultaneous water content prediction in golden melon.

Keywords: visible-near infrared spectroscopy, water content, golden melon fruit 


\section{Pendahuluan}

Buah melon merupakan buah yang digemari oleh masyarakat. Hal ini disebabkan oleh rasanya yang enak dan kandungan nutrisi yang terkandung didalamnya. Komoditas hortikultura, khususnya buah-buahan memiliki sifat yang mudah rusak. Ini dikarenakan komoditas buahbuahan mengandung kadar air yang tinggi. Kadar air merupakan besarnya kandungan air yang terdapat pada suatu bahan. Umumnya, nilai kadar air dinyatakan dalam nilai persen. Kadar air dalam buah dapat mempengaruhi tampilan, tekstur, dan juga rasa. Di samping itu, kadar air buah dapat menentukan tingkat kesegaran dan ketahanan simpan buah tersebut. Dalam industri produk pertanian, nilai kadar air penting untuk diketahui guna menentukan penanganan yang tepat bagi komoditas buah tersebut.

Penentuan nilai kadar air pada komoditas buah-buahan umumnya dilakukan dengan metode pengeringan menggunakan oven. Prinsipnya adalah menguapkan air pada sampel dengan suhu dan waktu tertentu hingga bobot sampel tidak berubah (konstan). Nilai persentase kehilangan bobot sebelum dan sesudah dikeringkan dihitung sebagai nilai kadar air. Penggunaan metode pengukuran kadar air dengan cara ini memerlukan waktu yang lama dan buah yang diukur harus didestruksi (rusak). Hal ini menyebabkan buah yang telah diukur kadar airnya tidak dapat dipasarkan.

Visible-Near Infrared Spectroscopy (Vis-NIRS) adalah suatu teknologi yang memanfaatkan interaksi antara gelombang elektromagnetik dan struktur molekul sampel (bahan organik) pada wilayah panjang gelombang yang mencakup sinar tampak (visible) dan inframerah dekat. Teknologi ini banyak digunakan untuk prediksi kualitas pada komoditas pertanian secara nondestruktif. Kelebihan dari teknologi Vis-NIRS yaitu pengukurannya cepat, simultan, tanpa memerlukan bahan kimia, dan tidak merusak sampel. Oleh karena itu sampel yang sudah diukur parameter kualitasnya menggunakan Vis-NIRS masih tetap dapat dipasarkan, karena kondisi sampel masih utuh.

Berkembangnya penelitian mengenai penggunaan Vis-NIRS didorong pula oleh kemajuan zaman dan teknologi yang menuntut penerapan teknologi yang dapat menghemat waktu dan ramah lingkungan. Teknologi Vis-NIRS untuk memprediksi kualitas pada produk pertanian telah dilakukan pada buah markisa (Maniwara et al., 2014), buah delima (Khodabakhshian et al., 2017), buah ceri (Shao et al., 2019), buah beri (Ribera et al., 2016), melon (Hadiwijaya et al., 2020) dan buah stroberi (Shen et al., 2018). Pada penelitian lain, Vis-NIRS dapat digunakan untuk mengelompokkan masing-masing komoditas buah-buahan dan sayuran buah berdasarkan spektra serapannya (Kusumiyati et al., 2019). Penerapan Vis-NIRS untuk memprediksi kadar air pada komoditas pertanian telah dilakukan pada buah jambu (Kusumiyati et al., 2019), daun sirih (Zhang et al., 2012), rumput (Jin et al., 2017), dan buah sawo (Kusumiyati et al., 2018). Namun, penerapan teknologi Vis-NIRS untuk prediksi kadar air buah melon golden belum pernah dilakukan. 
Maka dari itu, pada penelitian ini diaplikasikan teknologi Vis-NIRS untuk memprediksi kadar air pada buah melon Golden. Dikaji pula linieritas hubungan antara data spektra buah melon dan hasil pengukuran kadar air buah melon. Selain itu, diterapkan metode koreksi pada spektra original dan dipelajari pengaruhnya terhadap nilai linieritas. Tujuan utama dari penelitian ini yaitu memperoleh model kalibrasi yang memiliki nilai linieritas tinggi, tangguh, dan dapat diandalkan untuk memprediksi kadar air buah melon Golden menggunakan teknologi Vis-NIRS secara cepat dan simultan.

\section{Bahan dan Metode}

Pelaksanaan budidaya tanaman melon Golden dilakukan di daerah Jatinangor, Sumedang. Penanaman tanaman melon dilakukan di dalam rumah kasa (screenhouse). Tanaman melon yang digunakan pada penelitian ini adalah varietas Mekarsari SH-1. Pemananenan dilakukan pada tanaman melon yang berumur 65-70 hari setelah tanam (HST). Buah dipanen pada kondisi matang komersil. Sebelum dibawa ke laboratorium, sampel dibersihkan terlebih dahulu dari berbagai macam kotoran dan tanah. Sampel merupakan buah dengan kondisi yang baik, bebas hama \& penyakit, dan tidak terdapat cacat fisik. Jumlah sampel buah melon yang digunakan pada penelitian ini adalah sebanyak 82 sampel.

Spektrometer yang digunakan yaitu Nirvana AG410 pada rentang panjang gelombang 381$1065 \mathrm{~nm}$ (Gambar 1). Pengambilan data spektra sampel dilakukan cara meradiasi sampel pada 6 titik yang tersebar pada bagian pangkal, tengah, dan ujung buah melon. Spektra yang diperoleh dari pengambilan data spektra sampel adalah reflectance yang kemudian secara otomatis dikonversi menjadi absorbance. Data spektra sampel tersimpan dalam memory penyimpanan spektrometer. Kemudian data spektra ditransfer ke komputer menggunakan perangkat lunak (software) Integrated Software for Imagers and Spectrometers (ISIS).

Setelah data spektra pada sampel diambil, sampel kemudian didestruksi dan diiris tipis. Hasil irisan sampel ditimbang dalam aluminium foil cup untuk memperoleh bobot basah sampel. Sampel dikeringkan dalam oven dengan suhu $50^{\circ} \mathrm{C}$ hingga diperoleh bobot kering sampel. Kemudian nilai persentase kadar air sampel dihitung.

Data spektra bersama-sama dengan data hasil pengukuran kadar air dianalisis menggunakan software The Unscrambler 10.4 untuk penerapan koreksi pada spektra original dan regresi. Analisis multivariat digunakan untuk proses ekstraksi data spektra yang didapat dari sampel yang diradiasi Vis-NIRS. Namun sebelumnya, data spektra perlu untuk dikoreksi terlebih dahulu dengan tujuan memperbaiki variabel-variabel tidak seragam yang dapat mengurangi linieritas pada tahap pemodelan kalibrasi. Metode koreksi spektra yang diaplikasikan pada penelitian ini adalah orthogonal signal correction (OSC). Sementara itu, pendekatan regresi yang digunakan yaitu 
partial least squares regression (PLSR). Hasil analisis regresi berupa model kalibrasi, kemudian divalidasi menggunakan teknik validasi silang (cross validation). Selain penerapan validasi silang, model kalibrasi dievaluasi pula dengan mempertimbangkan nilai koefisien determinasi $\left(\mathrm{R}^{2}\right)$, principal component (PC), root mean squares error of calibration (RMSEC), root mean squares error of cross validation (RMSECV), dan ratio of performance to deviation (RPD).

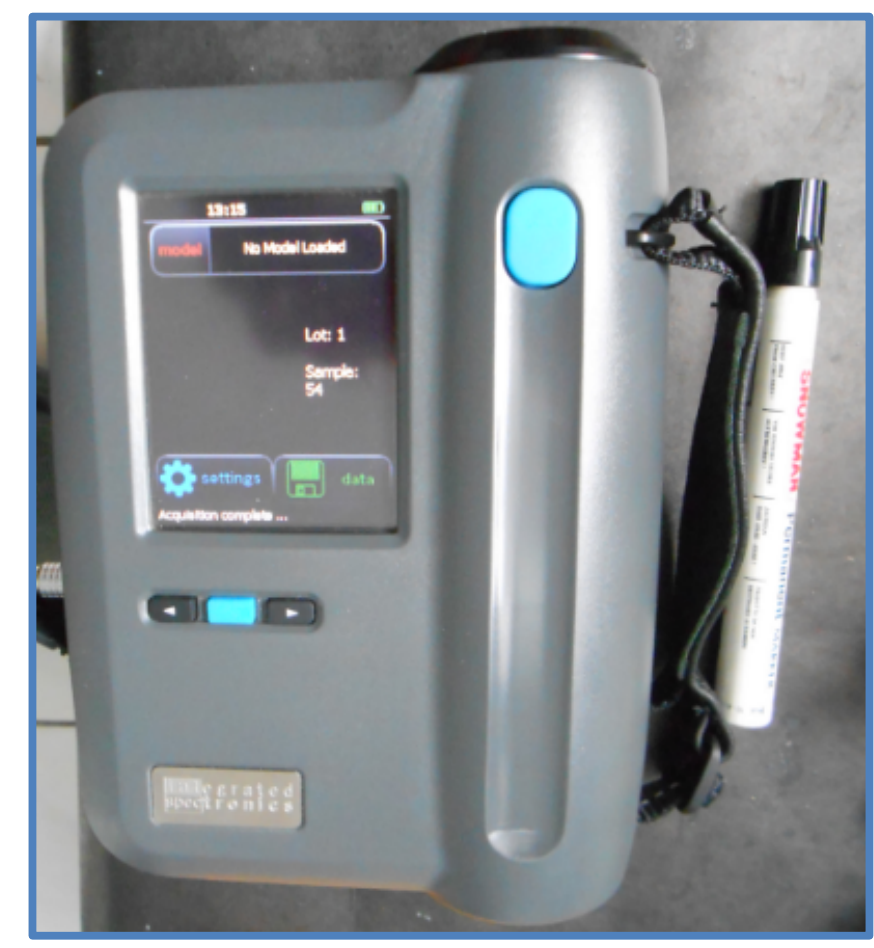

Gambar 1. Spektrometer Nirvana AG410.

\section{Hasil dan Pembahasan}

Grafik spektra pada 82 sampel buah melon Golden disajikan pada Gambar 2. Pada spektra absorban sampel buah melon terdapat beberapa puncak dan lembah yang muncul. Adanya puncak dan lembah diakibatkan oleh interaksi antara radiasi yang dipancarkan spektrometer pada panjang gelombang tertentu dan molekul senyawa yang terkandung dalam sampel. Panjang gelombang 970 nm berkorelasi dengan vibrasi ikatan O-H dari molekul air (Allen et al., 2012). Pada riset yang dilakukan oleh Zhang et al. (2012), dilaporkan bahwa panjang gelombang $760 \mathrm{~nm}$ berhubungan dengan pita serapan air. Temuan lain didapatkan oleh Martelo-Vidal \& Vázquez (2014) yang mengutarakan bahwa pita serapan air ditemukan pula pada panjang gelombang $950 \mathrm{~nm}$.

Pengukuran kadar air secara destruktif dilakukan untuk memperoleh data referensi yang selanjutnya akan digunakan dalam pengembangan model kalibrasi. Berdasarkan hasil pengukuran di laboratorium, kadar air buah melon Golden varietas Mekarsari SH-1 memiliki nilai yang berkisar diantara 94,6-96,5\% seperti yang ditampilkan pada Tabel 1. Hasil tersebut tidak berbeda jauh dengan prediksi kadar air berdasarkan Vis-NIRS pada spektra original $(94,6$ - 96,4\%) maupun OSC (94,7 - 96,4\%). Hasil analisis kalibrasi dan validasi dapat dilihat pada Tabel 1. 


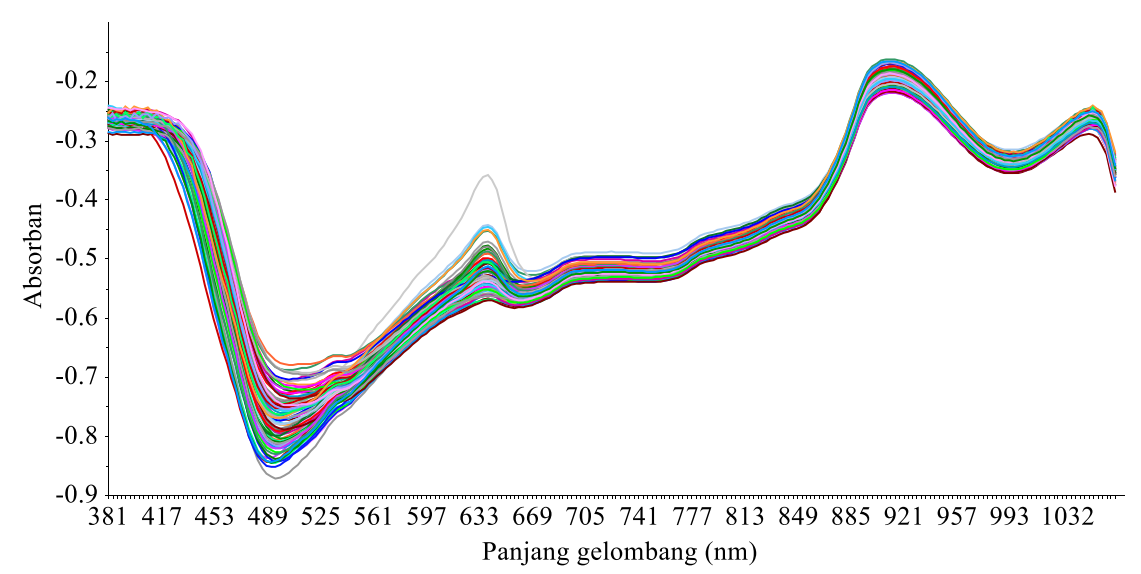

Gambar 2. Data spektra original hasil pengukuran pada sampel buah melon Golden

Tabel 1. Hasil analisis kalibrasi dan validasi

\begin{tabular}{ccccccccc}
\hline Spektra & Referensi & Prediksi Vis-NIRS & PC & \multicolumn{2}{c}{ Kalibrasi } & \multicolumn{2}{c}{ Validasi } & RPD \\
\cline { 5 - 7 } & $(\%)$ & $(\%)$ & & $\mathrm{R}^{2}$ & RMSEC & $\mathrm{R}^{2}$ & RMSECV & \\
\hline Original & $94,6-96,5$ & $94,6-96,4$ & 7 & 0,91 & 0,00095 & 0,89 & 0,00112 & 2,99 \\
OSC & $\mathbf{9 4 , 6 - 9 6 , 5}$ & $\mathbf{9 4 , 7 - 9 6 , 4}$ & $\mathbf{1}$ & $\mathbf{0 , 9 2}$ & $\mathbf{0 , 0 0 0 9 0}$ & $\mathbf{0 , 9 2}$ & $\mathbf{0 , 0 0 0 9 2}$ & $\mathbf{3 , 6 3}$ \\
\hline
\end{tabular}

Keterangan: $\mathrm{PC}=$ principal component, $\mathrm{R}^{2}=$ koefisien determinasi, $\mathrm{RMSEC}=$ root mean squares error of calibration, $\mathrm{RMSECV}=$ root mean squares error of cross validation, $\mathrm{RPD}=$ ratio of performance to deviation

Data spektra original sampel perlu dikoreksi untuk mereduksi efek hamburan cahaya, noises, dan berbagai gangguan spektra lainnya. Penerapan metode koreksi OSC pada spektra original buah melon mampu mereduksi jumlah PC menjadi 1. OSC adalah suatu metode pemrosesan data dengan tujuan membuang informasi yang tidak berkorelasi dengan target. Menurut Boháč et al. (2002), OSC dapat mereduksi sejumlah besar variabel $\mathrm{X}$, sehingga pemodelan kalibrasi PLSR menghasilkan model yang memiliki kemampuan prediksi yang lebih baik. Jumlah PC yang rendah lebih diharapkan pada model kalibrasi Vis-NIRS. Model kalibrasi dengan jumlah PC yang tinggi menandakan tingginya gangguan pada data spektra yang dianalisis (Jankovská \& Šustová, 2003).

Pemodelan kalibrasi dilakukan dengan meregresikan data spektra Vis-NIRS dan data referensi. Gambar 3 menampilkan model kalibrasi PLSR dan validasi pada masing-masing spektra. Garis regresi dan sebaran data warna biru merupakan hasil pemodelan kalibrasi, sedangkan garis dan sebaran data warna merah adalah hasil validasi. Penetapan model kalibrasi terbaik didasarkan pada koefisien determinasi $\left(\mathrm{R}^{2}\right)$ dan $\mathrm{RPD}$ yang tinggi, selain itu dipertimbangkan pula nilai error yang rendah. Model kalibrasi perlu divalidasi dengan tujuan untuk memverifikasi keakuratan model tersebut. Validasi dilakukan dengan teknik validasi silang (cross validation), 82 sampel diacak dan dibagi kedalam 20 segment, pada masing-masing segment terdapat 4 - 5 sampel. Kemudian 19 segment digunakan untuk memprediksi 1 segment, hal tersebut diulangi hingga keseluruhan segment diprediksi. Model kalibrasi yang baik juga harus memiliki 
nilai $\mathrm{R}^{2}$ kalibrasi dan RMSEC yang hampir sama dengan $\mathrm{R}^{2}$ validasi dan RMSECV. Rentang nilai koefisien determinasi berkisar antara nol (0) hingga satu (1).
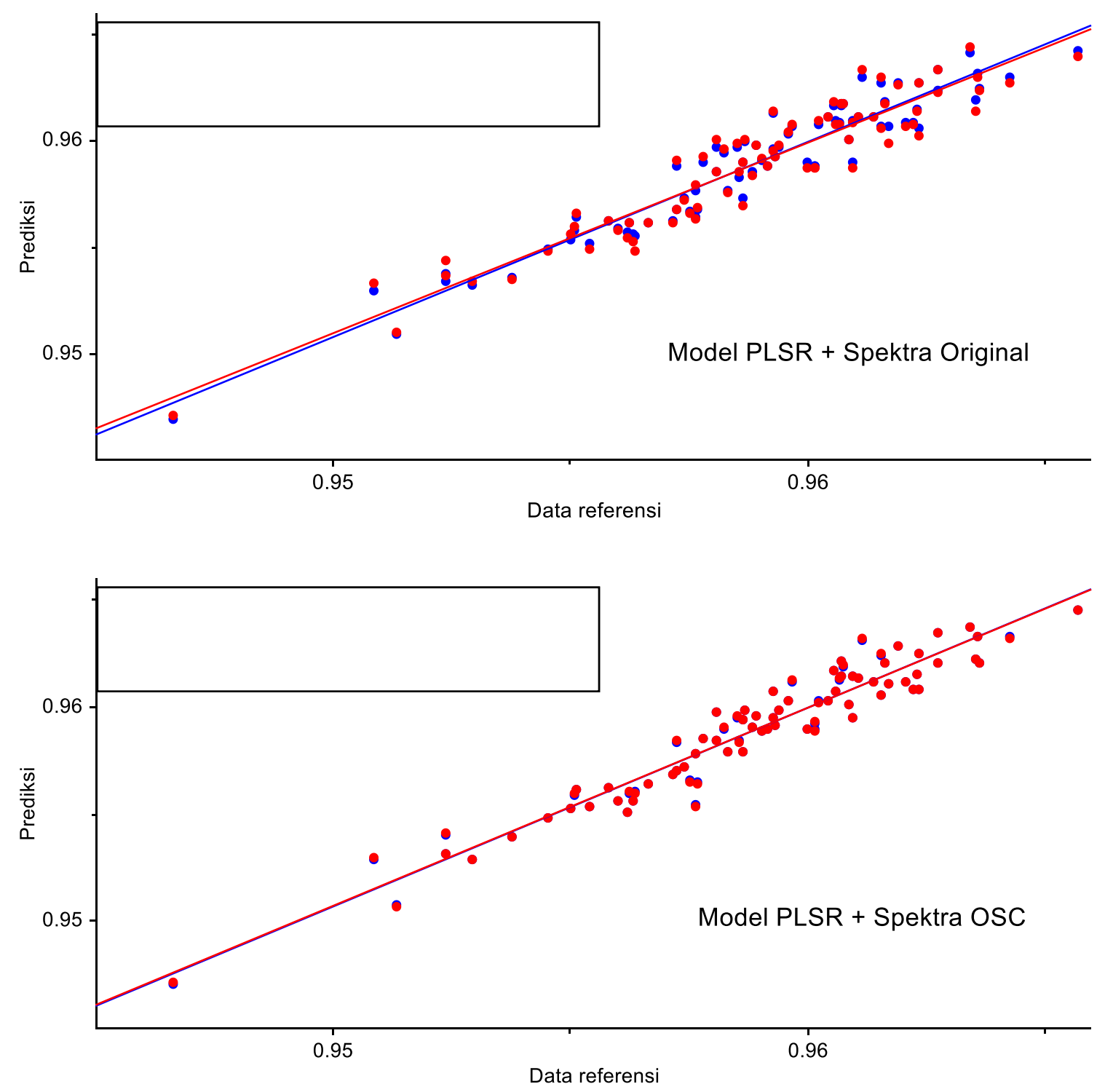

Gambar 3. Model kalibrasi yang dikembangkan dengan pendekatan PLSR dan validasi pada masing-masing spektra

Koefisien determinasi menjelaskan seberapa besar kemampuan dari variabel independen (data spektra Vis-NIRS) dalam menerangkan variasi pada variabel dependen (data referensi). Model kalibrasi yang mempunyai nilai koefisien determinasi mendekati 1 berarti model tersebut memiliki variabel independen yang mampu menjelaskan hampir seluruh variasi pada variabel dependen, hal ini berlaku pula sebaliknya. Pada penelitian ini, model kalibrasi terbaik diperoleh spektra OSC dengan menampilkan nilai $\mathrm{R}^{2}$ sebesar 0,92 dibanding spektra original yang hanya 0,91. Hasil tersebut sesuai dengan riset yang dikerjakan oleh Fan et al. (2018) bahwa penggunaan metode koreksi spektra OSC mampu meningkatkan linieritas model kalibrasi dengan nilai 0,99 pada pendugaan kandungan lemak daging babi. Studi lain melaporkan penggunaan Vis-NIRS dan OSC menghasilkan nilai $\mathrm{R}^{2}$ kalibrasi yang jauh lebih tinggi dari spektra original, yaitu sebesar 
0,99 pada estimasi likopen pada buah tomat (Saad et al., 2014). Nilai error (RMSEC dan RMSECV) yang diperoleh pada spektra OSC ialah 0,00090 dan 0,00092 tercatat lebih rendah dari spektra original. Error pada model kalibrasi dihitung dari selisih antara data referensi dan nilai kada air prediksi Vis-NIRS pada masing-masing sampel. Makin rendah nilai error, maka main baik pula model kalibrasi tersebut. Nilai RPD pada spektra OSC adalah 3,63, lebih tinggi dari spektra original yang hanya sebesar 2,99. RPD dihitung guna mengukur seberapa baik performa model kalibrasi yang telah dibangun (Brogna et al., 2018). Nicolaï et al. (2007) menyatakan bahwa nilai RPD lebih dari 3,0 menunjukkan bahwa model kalibrasi telah dikembangkan dengan baik dan dapat diandalkan untuk tahap prediksi.

\section{Kesimpulan}

Kadar air buah melon Golden dapat diprediksi dengan nilai akurasi yang tinggi menggunakan Vis-NIRS. Model kalibrasi terbaik ditampilkan oleh spektra yang telah dikoreksi dengan metode orthogonal signal correction (OSC) dengan nilai koefisien determinasi $\left(\mathrm{R}^{2}\right)$ kalibrasi, validasi, root mean squares error of calibration (RMSEC), root mean squares error of cross validation (RMSECV), dan ratio of performance to deviation (RPD) berturut-turut sebesar 0,92; 0,92; 0,00090; 0,00092 dan 3,63. Hasil tersebut mengindikasikan bahwa teknologi Vis-NIRS terbukti dapat diandalkan dalam memprediksi kadar air buah melon Golden secara cepat dan simultan.

\section{Daftar Pustaka}

Allen, T. J., Hall, A., Dhillon, A. P., Owen, J. S., \& Beard, P. C. (2012). Spectroscopic photoacoustic imaging of lipid-rich plaques in the human aorta in the 740 to $1400 \mathrm{~nm}$ wavelength range. Journal of Biomedical Optics, 17(6), 61209, 1-10. https://doi.org/10.1117/1.JBO.17.6.061209

Boháč, M., Loeprecht, B., Damborský, J., \& Schüürmann, G. (2002). Impact of Orthogonal Signal Correction (OSC) on the Predictive Ability of CoMFA Models for the Ciliate Toxicity of Nitrobenzenes. Quantitative Structure-Activity Relationships, 21(1), 3-11. https://doi.org/10.1002/1521-3838(200205)21:1<3::AID-QSAR3>3.0.CO;2-D

Brogna, N., Palmonari, A., Canestrari, G., Mammi, L., Dal Prà, A., \& Formigoni, A. (2018). Technical note: Near infrared reflectance spectroscopy to predict fecal indigestible neutral detergent fiber for dairy cows. Journal of Dairy Science, 101(2), 1234-1239. https://doi.org/10.3168/jds.2017-13319

Fan, Y., Liao, Y., \& Cheng, F. (2018). Predicting of intramuscular fat content in pork using near infrared spectroscopy and multivariate analysis. International Journal of Food Properties, 21(1), 1180-1189. https://doi.org/10.1080/10942912.2018.1460606

Hadiwijaya, Y., Kusumiyati, K., \& Munawar, A. A. (2020). PREDIKSI TOTAL PADATAN TERLARUT BUAH MELON GOLDEN (Cucumis melo L.) MENGGUNAKAN VISSWNIRS DAN ANALISIS MULTIVARIAT. Jurnal Penelitian Saintek, 25(2), 103-114. https://doi.org/10.21831/jps.v25i2.34487

Jankovská, R., \& Šustová, K. (2003). Analysis of cow milk by near-infrared spectroscopy. Czech Journal of Food Sciences, 21(4), 123-128. https://doi.org/10.17221/3488-cjfs

Jin, X., Shi, C., Yu, C. Y., Yamada, T., \& Sacks, E. J. (2017). Determination of Leaf Water Content 
by Visible and Near-Infrared Spectrometry and Multivariate Calibration in Miscanthus. Frontiers in Plant Science, 8(721), 1-8. https://doi.org/10.3389/fpls.2017.00721

Khodabakhshian, R., Emadi, B., Khojastehpour, M., Golzarian, M. R., \& Sazgarnia, A. (2017). Non-destructive evaluation of maturity and quality parameters of pomegranate fruit by visible/near infrared spectroscopy. International Journal of Food Properties, 20(1), 41-52. https://doi.org/10.1080/10942912.2015.1126725

Kusumiyati., Hadiwijaya, Y., \& Putri, I. E. (2018). Determination of water content of intact sapodilla using near infrared spectroscopy. IOP Conference Series: Earth and Environmental Science (Vol. 207). 20-21 Oktober 2018. https://doi.org/10.1088/1755-1315/207/1/012047

Kusumiyati., Hadiwijaya, Y., \& Putri, I. E. (2019). Non-Destructive Classification of Fruits Based on Vis-nir Spectroscopy and Principal Component Analysis. Jurnal Biodjati, 4(1), 89-95. https://doi.org/10.15575/biodjati.v4i1.4389

Kusumiyati., Hadiwijaya, Y., Putri, I. E., \& Mubarok, S. (2019). Water content prediction of "crystal" guava using visible-near infrared spectroscopy and chemometrics approach. IOP Conference Series: Earth and Environmental Science. https://doi.org/10.1088/17551315/393/1/012099

Maniwara, P., Nakano, K., Boonyakiat, D., Ohashi, S., Hiroi, M., \& Tohyama, T. (2014). The use of visible and near infrared spectroscopy for evaluating passion fruit postharvest quality. Journal of Food Engineering, 143, 33-43. https://doi.org/10.1016/j.jfoodeng.2014.06.028

Martelo-Vidal, M., \& Vázquez, M. (2014). Evaluation of Ultraviolet, Visible, and Near Infrared Spectroscopy for the Analysis of Wine Compounds. Czech Journal of Food Sciences, 32(1), 37-47. https://doi.org/10.17221/167/2013-CJFS

Nicolaï, B. M., Beullens, K., Bobelyn, E., Peirs, A., Saeys, W., Theron, K. I., \& Lammertyn, J. (2007). Nondestructive measurement of fruit and vegetable quality by means of NIR spectroscopy: A review. Postharvest Biology and Technology, 46(2), 99-118. https://doi.org/10.1016/j.postharvbio.2007.06.024

Ribera, A., Noferini, M., \& Rombolà, A. (2016). Non-destructive Assessment of Highbush Blueberry Fruit Maturity Parameters and Anthocyanins by Using a Visible/Near Infrared (vis/NIR) Spectroscopy Device: A Preliminary Approach. Journal of Soil Science and Plant Nutrition, 16(1), 174-186. https://doi.org/10.4067/S0718-95162016005000014

Saad, A. G., Jaiswal, P., \& Jha, S. N. (2014). Non-destructive quality evaluation of intact tomato using VIS-NIR spectroscopy. International Journal of Advanced Research, 2(12), 632-639.

Shao, Y., Xuan, G., Hu, Z., Gao, Z., \& Liu, L. (2019). Determination of the bruise degree for cherry using Vis-NIR reflection spectroscopy coupled with multivariate analysis. PLoS ONE, 14(9), 1-13. https://doi.org/10.1371/journal.pone.0222633

Shen, F., Zhang, B., Cao, C., \& Jiang, X. (2018). On-line discrimination of storage shelf-life and prediction of post-harvest quality for strawberry fruit by visible and near infrared spectroscopy. Journal of Food Process Engineering, 41(7), 1-8. https://doi.org/10.1111/jfpe.12866

Zhang, Q., Li, Q., \& Zhang, G. (2012). Rapid Determination of Leaf Water Content Using VIS/NIR Spectroscopy Analysis with Wavelength Selection. Spectroscopy: An International Journal, 27(2), 93-105. https://doi.org/10.1155/2012/276795 